\title{
Effects of Sodium Sulfate Attack on Concrete Incorporated with Drying-Wetting Cycles
}

\author{
Fang Liu $\mathbb{D}^{\mathbb{D}},{ }^{1}$ Zhanping You $\mathbb{D}^{\mathrm{D}}{ }^{2}$ Rui Xiong, ${ }^{3}$ and Xu Yang ${ }^{4}$ \\ ${ }^{1}$ Faculty of Transportation Engineering, Huaiyin Institute of Technology, Huai'an, Jiangsu 223003, China \\ ${ }^{2}$ Department of Civil and Environmental Engineering, Michigan Technological University, 1400 Townsend Drive, Houghton, \\ Michigan 49931, USA \\ ${ }^{3}$ School of Materials Science and Engineering, Chang'an University, Nan Erhuan Road (Middle Section), Xi'an, \\ Shaanxi 710064, China \\ ${ }^{4}$ School of Highway, Chang'an University, Nan Erhuan Road (Middle Section), Xi'an, Shaanxi 710064, China
}

Correspondence should be addressed to Fang Liu; fangliu@hyit.edu.cn

Received 25 April 2021; Revised 19 July 2021; Accepted 2 August 2021; Published 13 August 2021

Academic Editor: Peerapong Jitsangiam

Copyright ( $\odot 2021$ Fang Liu et al. This is an open access article distributed under the Creative Commons Attribution License, which permits unrestricted use, distribution, and reproduction in any medium, provided the original work is properly cited.

\begin{abstract}
It has been widely observed that sulfate attack can damage the durability of concrete. This research investigated the mass loss and damage degree of concrete under sodium sulfate attack incorporated with drying-wetting cycles. The impact factors, including water-binder ratio, solution concentration of sodium sulfate, fly ash content, curing time, and drying-wetting cycle system, were observed to influence the sodium sulfate attack by the mass loss rate and damage degree at regular time intervals. Also, the hydrates of sulfate-attacked samples were analyzed using X-ray diffraction. Results indicated that a high water-binder and highconcentration sodium sulfate solution could accelerate the transportation of sulfate ion inside the concrete and the deterioration degree of concrete. Appropriate fly ash and longer curing time can effectively improve the internal pore structure of concrete to reduce the sulfate corrosion damage. The sulfate ion erosion and deterioration degree of the concrete are synchronously intensified along with the increase of the baking-immersing time ratio. The trend of the predicted life for concrete is basically consistent with the damage evolution result, indicating the feasibility of the Weibull distribution model to predict the service life of concrete under sodium sulfate attack incorporated with drying-wetting cycles.
\end{abstract}

\section{Introduction}

External sulfate attack on concrete is a complex interaction between sulfate and the concrete, including physical, chemical, and mechanical processes, leading to the decrease of concrete durability $[1,2]$. In some particular scenarios, e.g., concrete piers of sea-crossing bridges in tidal zones and port docks in splash zones, concrete structures have to be simultaneously subjected to the combined effects of dryingwetting cycles and sulfate attack. Compared to structural concrete continuously immersed in the sulfate solution, the damage of those structural concretes is significantly accelerated under the dynamical sulfate attacking incorporated with drying-wetting cycles [3-7]; however, its degradation mechanism is so complicated $[8-10]$ that there is still a large gap between sulfate attacking and mechanical behaviors.

Under the action of drying-wetting cycles and sulfate attack, concrete is not only chemically corroded but also accompanied by physical corrosion [11]. The transmission of sulfate ions $\left(\mathrm{SO}^{2-}{ }_{4}\right)$ in concrete can be divided into the wetting state and drying state. During the wetting state, after the $\mathrm{Na}_{2} \mathrm{SO}_{4}$ solution is adsorbed, on the surface of the concrete specimens, not only physically but also chemically, sulfate ions enter the interior of the concrete with moisture due to capillary action. After being saturated in the solution, sulfate ions migrate into deeper parts of the concrete due to the diffusion effect caused by the concentration gradient. During the migration, reactions between the cement hydration products and sulfate ions 
occur, forming expansive erosion products [12]. Hence, concrete in the wetting state, within the influence depth of drying-wetting cycles, is subjected to both water convection due to capillary action and diffusion due to concentration gradients. During the drying state, the moisture evaporation from concrete results in the crystallization of salt in the pore solution from the surface and inside. Thus, the drying-wetting cycle accelerates the fatigue failure in the concrete hole wall, which explains why the deterioration of concrete under drying-wetting cycles is more severe than that in continuous soaking conditions.

The damage theory is believed to be suitable for the study of concrete [13]. The damage failure process of concrete under the influence of corrosion and other factors reflects the loss of the bearing capacity of concrete structures with the corrosion time. According to damage mechanics [14], using the strain equivalence principle, the damage variable of the concrete $D_{\mathrm{t}}$ after the corrosion age $t$ is expressed by the equation: $D_{\mathrm{t}}=1-E_{t} / E_{0}$, where $E_{t}$ represents the dynamic elastic modulus of the concrete at corrosion age $t$ and $E_{0}$ represents the initial dynamic elastic modulus of concrete. For concrete under macrodamage such as drying-wetting cycles, although the damage mechanisms are different, the damage failure process is essentially a process involving the internal deterioration behavior of the materials. The physical quantity of damage is believed to be the commonality of various failure processes.

Currently, the Weibull distribution is the most widely used reliability analysis approach, especially in the data processing of various life tests. The Weibull distribution is very inclusive, with rich curve shapes. A large number of different features can be obtained by adjusting parameters. Li et al. [15] showed that the flexural fatigue life distributions of mechanical sand concrete and river sand concrete were in line with the two-parameter Weibull distribution. Xiao et al. [16] reported that the Weibull model could accurately describe the damage variation for the recycled concrete under sulfate attack and freeze-thaw cycles. Dong et al. [17] described the freeze-thaw damage process for the lightweight aggregate concrete using an improved Weibull two-parameter probability model. However, there have been few studies on the fitting of concrete damage degree and service life prediction based on the Weibull distribution model for the influencing factors in the coupling effects of dryingwetting cycles and sulfate attack.

Motivated by current need, this research aims to evaluate the effects of sulfate attack incorporated with drying-wetting cycles on mortar specimens. At regular time intervals, the current study measured and analyzed the mass loss rate and damage degree of the mortar specimens by impact factors. The multivariate Weibull distribution model of concrete life prediction established by Guan $[18,19]$ in accordance with the actual situation was referred to predict the service life of concrete. Additionally, the hydrates of samples were analyzed using X-ray diffraction (XRD). This research will be beneficial to provide a basic approach to assess the durability damage and to predict the service life of concrete structures exposed to sulfate-rich conditions.

\section{Materials, Methods, and Calculations}

2.1. Materials. Ordinary Portland cement with the strength grade 42.5 was used in this study, which was produced by Jidong Cement Company in Shaanxi Province, China, and Class F fly ash produced by Sanmenxia Thermal Power Plant was utilized. The chemical contents of the cement and fly ash are detailed in Table 1. The coarse aggregate was limestone with an apparent density of $2.714 \mathrm{~g} / \mathrm{cm}^{3}$, ranging between 5 and $25 \mathrm{~mm}$. River sand with an apparent density of $2.630 \mathrm{~g} /$ $\mathrm{cm}^{3}$ and with a fineness modulus of 2.74 was used in the experiment. A polycarboxylic acid water-reducing agent was chosen as the concrete admixture and produced by a building scientific research institute to improve the workability of fresh concretes. The above materials were all mixed with tap water complying with the GB 50081-2002 [20]. The mix proportion of concrete is shown in Table 2. Prismatic specimens of $100 \mathrm{~mm} \times 100 \mathrm{~mm} \times 400 \mathrm{~mm}$ were prepared for the test.

2.2. Experimental Scheme. The test scheme of concrete under drying-wetting cycles and sodium sulfate attack is shown in Table 3.

2.3. Experiment Method. The standardly cured specimens for $28 \mathrm{~d}$ (except for specimens with different curing time) were baked at $60^{\circ} \mathrm{C}$ for $24 \mathrm{~h}$ in the oven and then cooled to room temperature. The test was carried out in accordance with the designed drying-wetting cycle system. As for G1, the dried specimens were immersed in the sodium sulfate solution for 10 hours, followed by drying for 1 hour at room temperature, then were baked at $60^{\circ} \mathrm{C}$ for $36 \mathrm{~h}$ in the oven, and finally cooled for $1 \mathrm{~h}$ in the air. As for G2, the dried specimens were immersed in the sodium sulfate solution for 23 hours, followed by drying for 1 hour at room temperature, then were baked at $60^{\circ} \mathrm{C}$ for $23 \mathrm{~h}$ in the oven, and finally cooled for $1 \mathrm{~h}$ in the air. The newly prepared corrosion solution replaced the original one every $20 \mathrm{~d}$, and each corrosion container was equipped with a lid to ensure that the sulfate solution concentration remained essentially unchanged as the corrosion environment of concrete specimens. The test site of the dryingwetting cycles for the concrete specimen is shown in Figure 1.

\subsection{Calculations}

2.4.1. Mass Loss Rate. Specimens with the size of $100 \mathrm{~mm} \times 100 \mathrm{~mm} \times 400 \mathrm{~mm}$ were used, and three replicates were made to verify the reproducibility of results in this experiment. The mass loss rate of the concrete specimen was calculated using the following equation:

$$
\Delta W_{t}=\frac{W_{0}-W_{t}}{W_{0}} \times 100 \%,
$$


TABLE 1: Chemical contents of cement/fly ash based on XRF analysis (\% by mass).

\begin{tabular}{lcccccccc}
\hline Main oxide & $\mathrm{CaO}$ & $\mathrm{SiO}_{2}$ & $\mathrm{Al}_{2} \mathrm{O}_{3}$ & $\mathrm{Fe}_{2} \mathrm{O}_{3}$ & $\mathrm{MgO}$ & $\mathrm{Na}_{2} \mathrm{O}$ & $\mathrm{K}_{2} \mathrm{O}$ & $\mathrm{SO}_{3}$ \\
\hline Cement & 60.28 & 21.7 & 5.66 & 3.12 & 1.52 & 0.37 & 0.55 & 2.1 \\
Fly ash & 3.93 & 53.25 & 28.75 & 4.94 & 1.59 & 0.54 & 1.92 & 1.7 \\
\hline
\end{tabular}

TABLE 2: Mix proportion of concrete.

\begin{tabular}{lccccccc}
\hline Water-binder ratio & $\begin{array}{c}\text { Cement } \\
\mathrm{kg} \cdot \mathrm{m}^{-3}\end{array}$ & $\begin{array}{c}\text { Fly ash } \\
\mathrm{kg} \cdot \mathrm{m}^{-3}\end{array}$ & $\begin{array}{c}\text { Water } \\
\mathrm{kg} \cdot \mathrm{m}^{-3}\end{array}$ & $\begin{array}{c}\text { Sand } \\
\mathrm{kg} \cdot \mathrm{m}^{-3}\end{array}$ & $\begin{array}{c}\text { Coarse aggregate } \\
\mathrm{kg} \cdot \mathrm{m}^{-3}\end{array}$ & $\begin{array}{c}\text { Water-reducing agent } \\
\mathrm{kg} \cdot \mathrm{m}^{-3}\end{array}$ & $\begin{array}{c}\text { 28 d flexural strength } \\
(\mathrm{MPa})\end{array}$ \\
\hline 0.35 & 440 & 0 & 154 & 649 & 1206 & 2.64 & 6.64 \\
0.40 & 440 & 0 & 176 & 642 & 1192 & 1.54 & 5.91 \\
& 308 & 132 & 176 & 642 & 1192 & 0.88 & 0.88 \\
0.45 & 220 & 220 & 176 & 642 & 1192 & 0 & 3.28 \\
\\
\hline
\end{tabular}

TABLE 3: Experimental scheme of concrete under drying-wetting cycles and sodium sulfate attack.

\begin{tabular}{lcccc}
\hline Specimen code & Water-binder ratio & $\begin{array}{c}\text { Concentration of sodium sulfate } \\
\text { (mass fraction) }\end{array}$ & $\begin{array}{c}\text { Drying-wetting cycle system } \\
\text { (baking-immersing time ratio) }\end{array}$ & Times of drying-wetting cycles \\
\hline N10G1 & 0.40 & 10 & $(36+1) \mathrm{h}:(10+1) \mathrm{h}$ & 90 \\
N5G1 & 0.40 & 5 & $(36+1) \mathrm{h}:(10+1) \mathrm{h}$ & 90 \\
N10G1R35 & 0.35 & 10 & $(36+1) \mathrm{h}:(10+1) \mathrm{h}$ & 90 \\
N10G1R45 & 0.45 & 10 & $(36+1) \mathrm{h}:(10+1) \mathrm{h}$ & 90 \\
N10G1F30 & 0.40 & 10 & $(36+1) \mathrm{h}:(10+1) \mathrm{h}$ & 90 \\
N10G1F50 & 0.40 & 10 & $(36+1) \mathrm{h}:(10+1) \mathrm{h}$ & 90 \\
N10G1Y90 & 0.40 & 10 & $(36+1) \mathrm{h}:(10+1) \mathrm{h}$ & 90 \\
N10G1Y300 & 0.40 & 10 & $(36+1) \mathrm{h}:(10+1) \mathrm{h}$ & 90 \\
N10G2 & 0.40 & 10 & $(23+1) \mathrm{h}:(23+1) \mathrm{h}$ & \\
\hline
\end{tabular}

Note. N-sodium sulfate, G-drying-wetting cycle system, R-water-binder ratio, F-fly ash, and Y-curing time. The numbers after $\mathrm{N}$ stand for the sulfate concentration, the number after $\mathrm{G}$ stands for two kinds of drying-wetting cycle system, the number after $\mathrm{R}$ stands for the decimal value of the water-binder ratio, the number after $\mathrm{F}$ stands for the content of fly ash, and the number after $\mathrm{Y}$ stands for days of precuring.

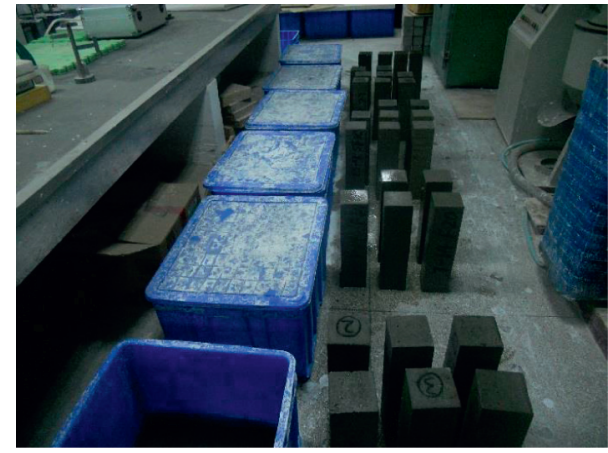

FIGURE 1: Test of sodium sulfate attack on concrete under dryingwetting cycles.

where $\Delta W_{t}$ represents the mass loss rate of concrete specimens at corrosion age $t$, (which is calculated as the average of the three specimens, \%), $W_{0}$ represents the mass of concrete specimens before corrosion, $g$, and $W_{t}$ represents the mass of concrete specimens at corrosion age $t, \mathrm{~g}$.

2.4.2. Damage Degree. The dynamic elastic modulus $E_{d 0}$ for the concrete specimens before erosion was measured by the DT-16 concrete dynamic modulus tester. The dynamic elastic modulus $E_{d t}$ of concrete specimens at corrosion age $t$ was measured every $10 \mathrm{~d}$ ( 5 cycles) during the erosion process. The damage degree $D$ is calculated using the following equation:

$$
D=1-\frac{E d t}{E_{d 0}}
$$

where $D$ represents the damage degree, $E_{d t}$ represents the dynamic elastic modulus of concrete specimens at corrosion age $t$, and $E_{d 0}$ represents the dynamic elastic modulus of concrete specimens before corrosion

\section{Results and Discussion}

\subsection{Mass Loss Rate}

3.1.1. Influence by Water-Binder Ratio on the Mass Loss Rate. The variation of the mass loss rate of concrete with different water-binder ratios is shown in Figure 2.

The change law of the mass loss rate of concrete specimen N10G1R35 over the number of drying-wetting cycles can be divided into two stages: accelerated decline in the first stage and slow rise in the second stage. The change law of the mass loss rate of concrete specimen N10G1 over the number of drying-wetting cycles can also be divided into two stages: accelerated decline and decline. The change law of the mass loss rate of concrete specimen N10G1R45 over the number of drying-wetting cycles can be divided into three stages: accelerated decline, decline, and rise. Concretes with different water-binder ratios all have an accelerated decline period, which is related to the drying-wetting cycle system 


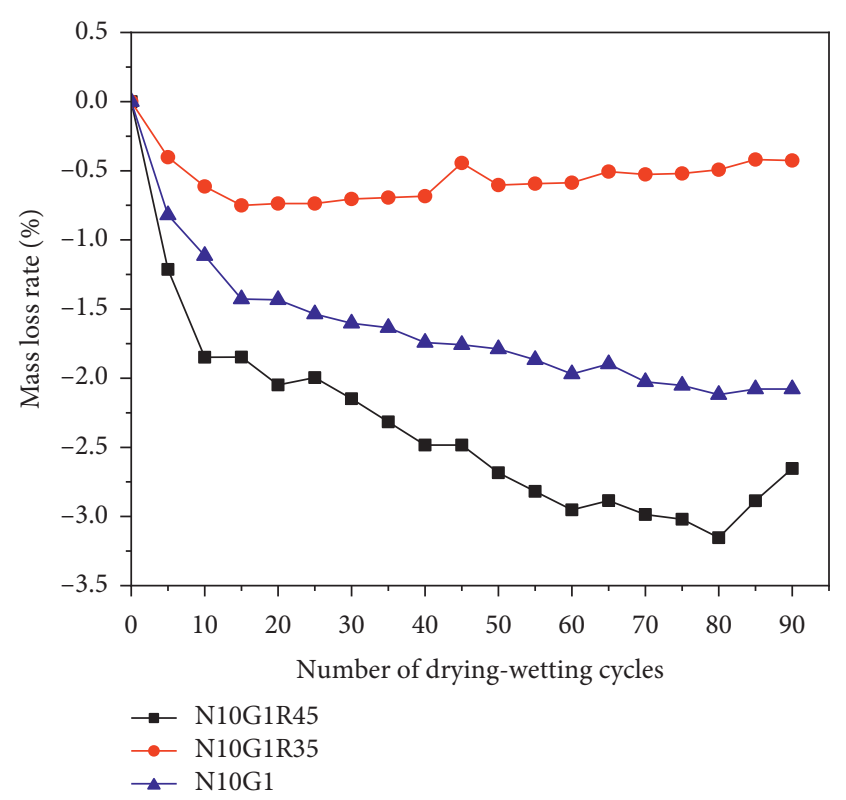

FIgURe 2: Variation of the mass loss rate of concrete with different water-binder ratios.

and the incomplete hydration of the concrete. After 90 cycles of drying-wetting, the mass loss rates of concrete specimens N10G1R35, N10G1, and N10G1R45 were $-0.426 \%$, $-2.078 \%$, and $-2.654 \%$, respectively. In the early stage of erosion, expansive erosion products fill micropores and cracks in the matrix except for water absorption and further hydration, so the mass of concrete specimens increases and the mass loss rate appears negative. The lower the waterbinder ratio of concrete, the denser the internal structure, and the smaller the porosity, the slower the diffusion rate of sulfate ions. Therefore, the lower the water-binder ratio, the smaller the drop in the mass loss rate of concrete.

The damaged specimen N10G1R45 after 90 cycles of drying-wetting is presented in Figure 3. It can be seen from Figure 3 that the edges and corners of the concrete specimens are damaged and peeled, some of the stones inside the concrete are exposed, and there are different degrees of cracks on the molding surface.

3.1.2. Influence on Mass Loss Rate under Drying-Wetting Cycles and $5 \% \mathrm{Na}_{2} \mathrm{SO}_{4}$. Figure 4 depicts the variation of the mass loss rate of concrete specimen N5G1 over the number of drying-wetting cycles. The variation of the mass loss rate of concrete specimen N5G1 with increasing cycles of dryingwetting is basically the same as that of concrete specimen N10G1. The mass loss rate can be divided into two stages: accelerated decline and decline. In the $5 \% \mathrm{Na}_{2} \mathrm{SO}_{4}$ solution, the absolute value of the slope of the concrete mass loss rate in the accelerated decline stage and the decline stage is less than that in the $10 \% \mathrm{Na}_{2} \mathrm{SO}_{4}$ solution, which indicates that the high-concentration solution accelerates the chemical reaction between sulfate ions and cement hydration products [21]. After 90 cycles of drying-wetting, the mass loss rate of concrete specimens N5G1 was $-1.273 \%$, while that of N10G1 was $-2.078 \%$.

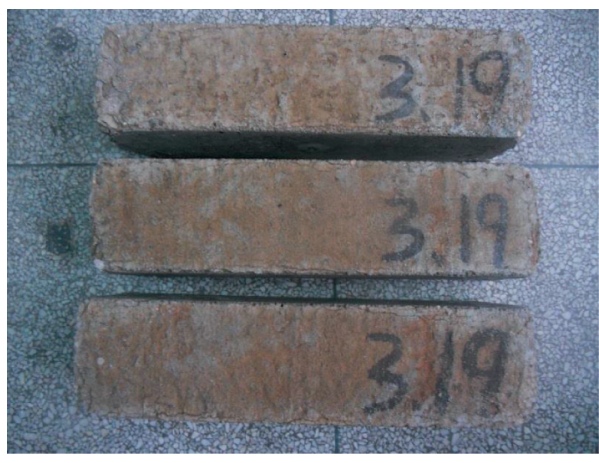

FIGURE 3: Appearance damage of specimens N10G1R45 after 90 cycles of drying-wetting.

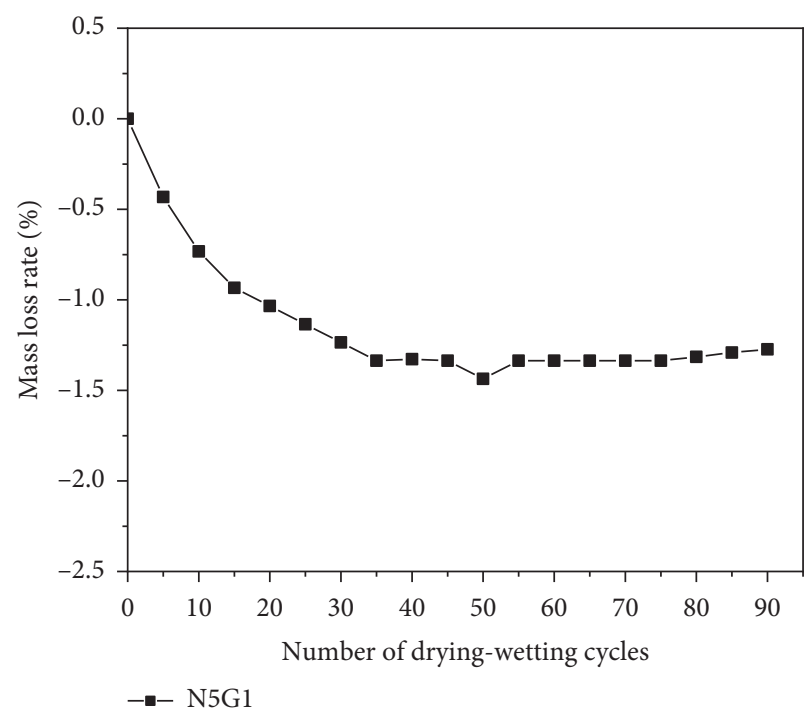

FIgURE 4: Variation of the mass loss rate of concrete under $5 \%$ $\mathrm{Na}_{2} \mathrm{SO}_{4}$ attack.

3.1.3. Influence of Fly Ash Content on the Concrete Mass Loss Rate. Figure 5 delineates the variation of the concrete mass loss rate with different fly ash contents as the number of drying-wetting cycles increases. The mass loss rate of concrete mixed with fly ash under $10 \% \mathrm{Na}_{2} \mathrm{SO}_{4}$ and dryingwetting cycles can be divided into three stages: accelerated decline, rise, and accelerated rise. After 90 cycles of dryingwetting, the mass loss rates of concrete samples N10G1F30 and N10G1F50 were $0.619 \%$ and $2.347 \%$, respectively. The mass loss rate of fly ash concrete is significantly greater than that of concrete without fly ash (N10G1). The greater the amount of fly ash, the higher the spalling degree of the concrete surface at a later period; consequently, the greater the mass loss rate.

3.1.4. Influence of Curing Time on Concrete Mass Loss Rate. Figure 6 shows the variation of the mass loss rate of concrete with increasing curing time. The variation of the mass loss rate of the concrete specimens N10G1Y90 and N10G1Y300 is almost the same, which can be divided into three stages. The first stage is the accelerated descending stage, the second 


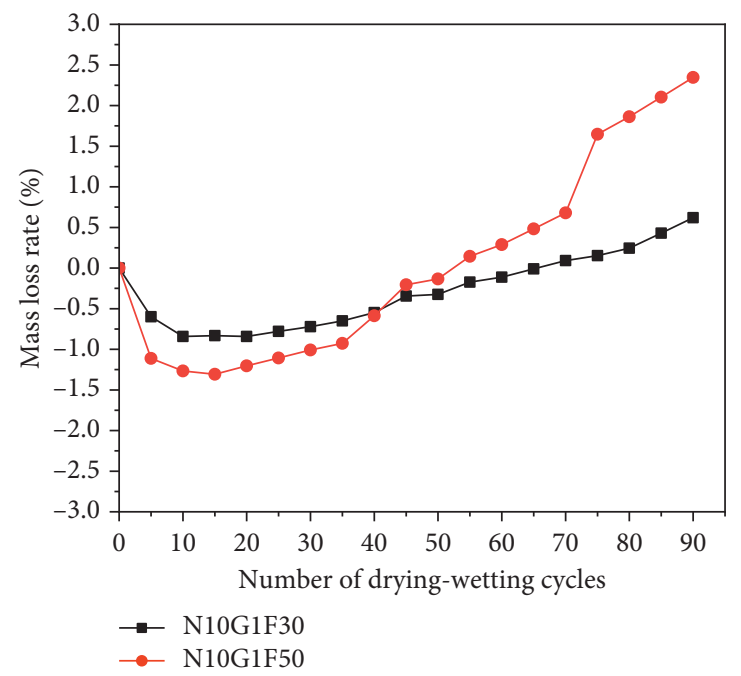

FIGURE 5: Variation of the mass loss rate of concrete with different fly ash contents.

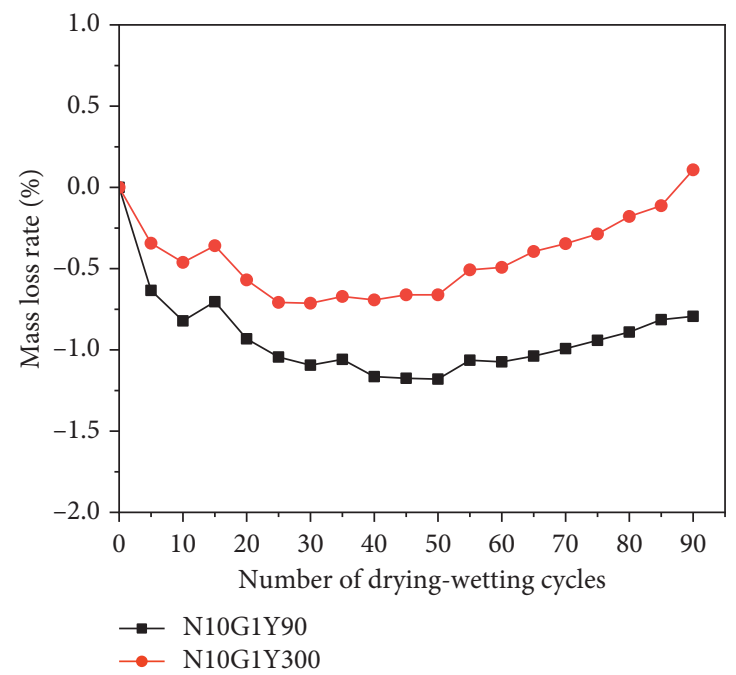

Figure 6: Variation of the mass loss rate of concrete with increasing curing time.

stage is the descending stage, and the third stage is the slow ascending stage. After 90 cycles of drying-wetting, the mass loss rates of the concrete specimens N10G1Y90 and N10G1Y300 were $-0.794 \%$ and $0.107 \%$, respectively. The longer the curing time, the more complete the hydration of the concrete, so the accelerated decline of the concrete mass loss rate with the lengthier curing time is smaller. The longer the curing time, the smaller the absolute value of the slope of concrete mass loss rate at decreasing section, that is, the smaller the rate of decrease.

3.1.5. Influence of the Drying-Wetting Cycle System on the Concrete Mass Loss Rate. Figure 7 depicts the variation of the mass loss rate of concrete with different drying-wetting cycle systems. The mass loss rate of concrete specimen N10G2 has the same variation law with the number of drying-wetting cycles, while the degree of decline is different compared to specimen N10G1. The mass loss rate can be divided into two stages, the accelerated descent stage and the descent stage. After 90 cycles of drying-wetting, the mass loss rate of concrete specimen N10G2 reached $-2.669 \%$. In both the accelerated descent stage and the descent stage, the decrease in the mass loss rate of concrete specimen N10G2 is greater than that of concrete specimen N10G1. The deterioration of the concrete aggravates with the increase of the baking-immersing time ratio [22]; however, due to the different baking-immersing time ratios, the influence on the mass loss rate of concrete specimens is more apparent than that of sulfate attack.

3.2. Damage Analysis and Service Life Prediction of Concrete under Drying-Wetting Cycles and Sodium Sulfate Attack. Since the size of the test specimen is $100 \mathrm{~mm} \times 100 \mathrm{~mm} \times 400 \mathrm{~mm}$, the aspect ratio is relatively large, and the damage calculation model can be a surface model. Also, during the drying-wetting cycles, the concrete 


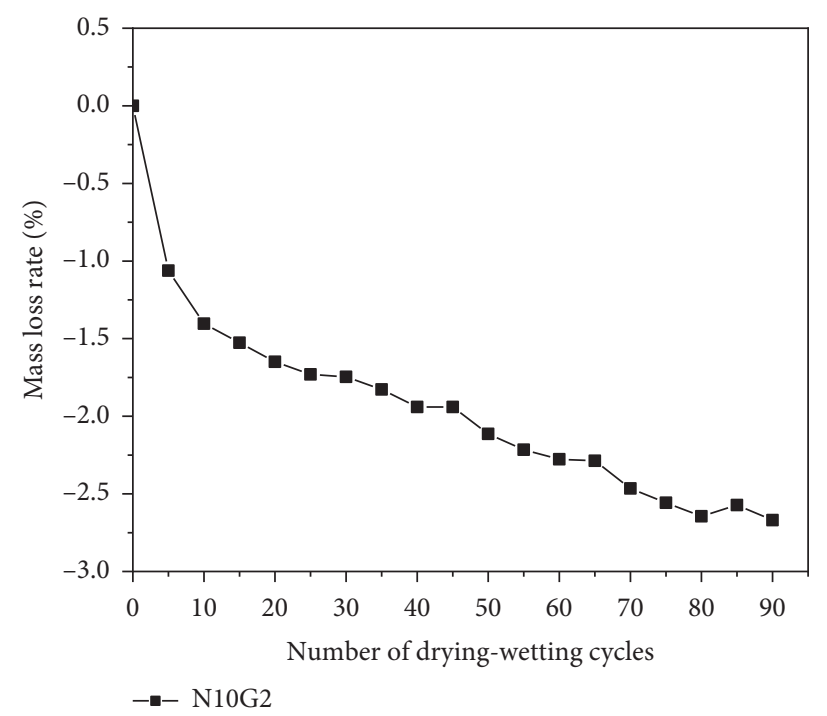

FIgURe 7: Variation of the mass loss rate of concrete with different drying-wetting cycle systems.

specimen is immersed in the solution or placed in the oven. The surrounding conditions of the cross section are subjected to the same boundary conditions. Hence, this study refers to the multivariate Weibull distribution model of concrete life prediction established by Guan [18, 19] in accordance with the actual situation. The following equation is used to fit the experimental data:

$$
E(D)=N^{-2} \sum_{i=0}^{(N / 2)-1} 4(N-2 i-1)\left\{1-\exp \left\{-\left[\lambda_{i}\left(0.001 \mathrm{~m}-k_{0} \lambda_{i}^{-1}\right)_{+}\right]^{\alpha}\right\}\right\}
$$

where $N$ is the equal fraction calculated on each side of the section and is taken as an even number, $m$ is the number of drying-wetting cycles related to the time scale, $k_{0}$ is the undetermined proportional constant, and $\alpha$ and $\lambda_{i}$ are the shape factor and scale factor of Weibull distribution, respectively. The subscript "+" means that when the value in the brackets is negative, the value is taken as 0 ; otherwise, the value is unchanged.

Assuming that the scale factor changes nonlinearly along the cross section, the scale factor of the $i$ th layer is shown as follows:

$$
\lambda_{i}=\lambda_{0}+v(i+0.5)^{-1},
$$

where $\lambda_{0}$ is the uniform scale parameter to be determined, $v$ is the gradient factor to be determined, and $i=0,1, \ldots . . .,(N / 2-1)$.

The concrete will expand at the early stage of the experiment under drying-wetting cycles and sulfate attack, so the relative dynamic elastic modulus is greater than 1 , and the damage degree is negative at the time. When the damage degree is negative, it is considered that no damage occurs to the concrete, and the damage degree is set as zero.

\subsubsection{Influence of Water-Binder Ratio on Concrete Damage.} Figure 8 illustrates the variation trend and the fitting curve of the damage degree of concrete with different water-binder ratios.
The concrete damage degree under drying-wetting cycles and $10 \% \mathrm{Na}_{2} \mathrm{SO}_{4}$ increases with the number of dryingwetting cycles. There is no damage initially, but after a certain cycle, damage occurs according to the data in Figure 8 . The more the drying-wetting cycles, the greater the degree of damage; the higher the water-binder ratio, the earlier the damage occurs and the greater the final damage degree is. After 90 cycles of drying-wetting, the concrete specimen N10G1R35 has a damage degree of only 0.0285 . The squared $R^{2}$ of the correlation coefficient after fitting is 0.95000 , indicating that the fitting accuracy is good, as shown in Figure 8(a). After 90 cycles of drying-wetting, the damage degree of the concrete specimen N10G1 is 0.2025 , and the squared $R^{2}$ of the correlation coefficient after fitting is 0.98299. The fitting accuracy is better, as shown in Figure 8(b). After 90 cycles of drying-wetting, the damage degree of the concrete specimen N10G1R45 reaches 0.4046, and the squared $R^{2}$ of the correlation coefficient after fitting is 0.99083 . The fitting accuracy is the best, as shown in Figure $8(\mathrm{c})$. The water-binder ratio is a crucial factor to control the damage of concrete subjected to sulfate attack [23]. Concrete with a higher water-binder ratio has more porosity, which accelerates the diffusion rate of sulfate ions in the concrete and increases the degree of concrete damage.

3.2.2. Influence on Concrete Damage Degree under DryingWetting Cycles and 5\% $\mathrm{Na}_{2} \mathrm{SO}_{4}$. The variation trend and 


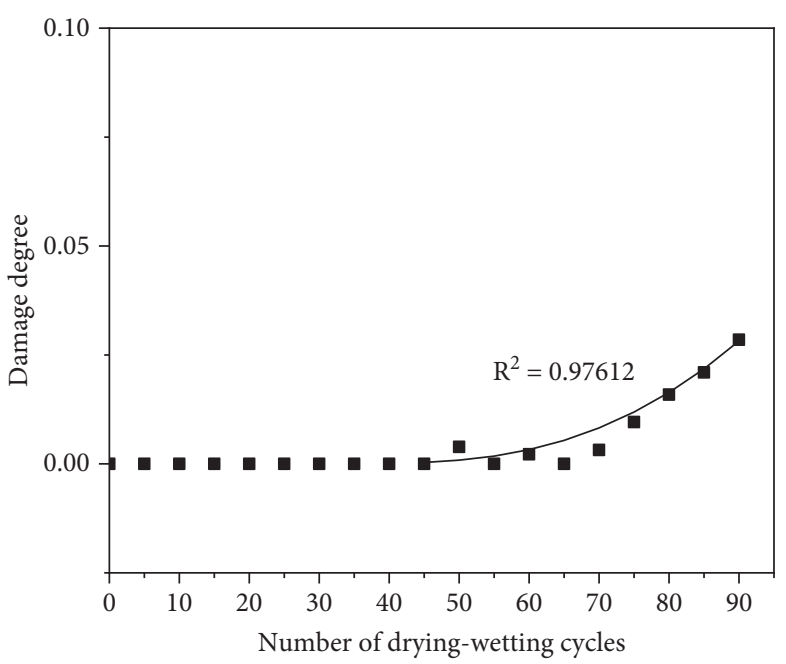

- N10G1R35

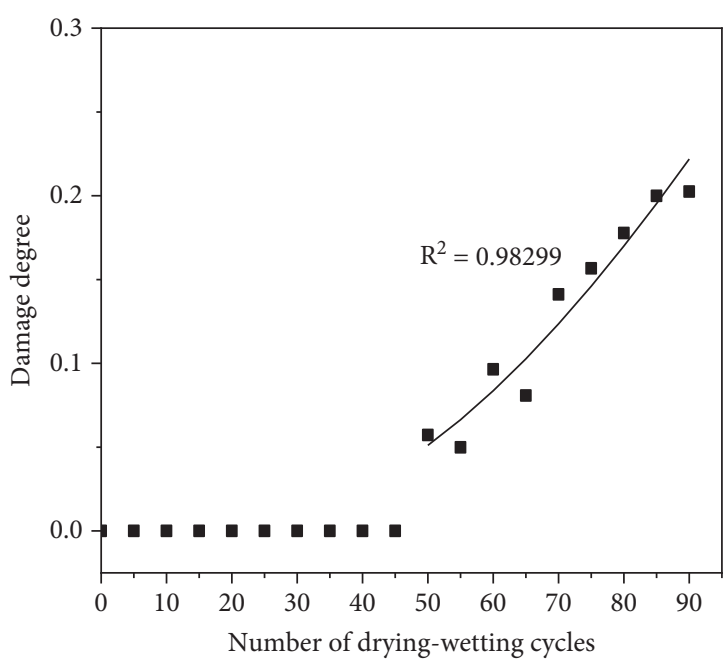

- N10G1

(a)

(b)

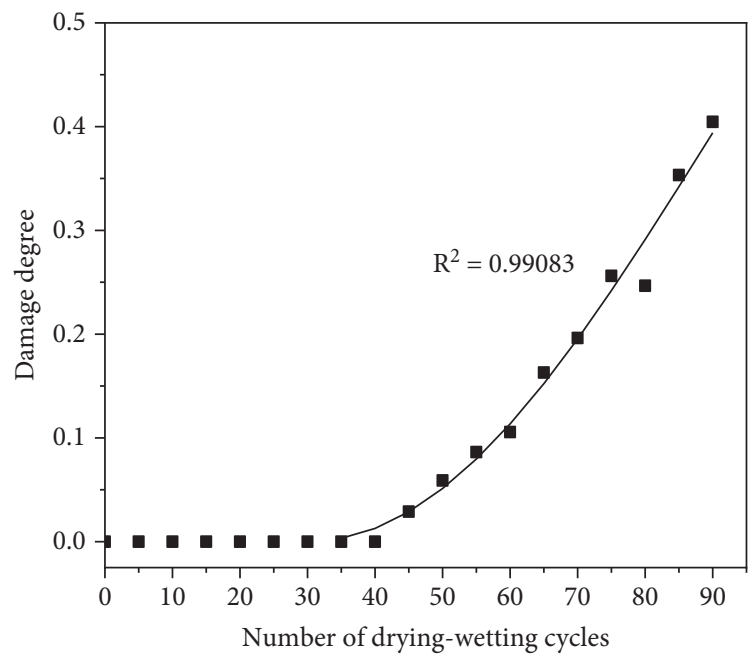

- N10G1R45

(c)

FiguRE 8: Variation of the concrete damage degree with different water-binder ratios. (a) N10G1R35. (b) N10G1. (c) N10G1R45.

fitting curve of the damage degree of concrete under dryingwetting cycles and $5 \% \mathrm{Na}_{2} \mathrm{SO}_{4}$ attack are shown in Figure 9.

The trends of the concrete damage degree under dryingwetting cycles and $5 \% \mathrm{Na}_{2} \mathrm{SO}_{4}$ are very similar to that of $10 \%$ $\mathrm{Na}_{2} \mathrm{SO}_{4}$ (Figure 8). There is no damage initially, and then, damage occurs after a certain cycle. The more the cycles of drying-wetting, the greater the damage. After 90 cycles of drying-wetting, the damage degree of concrete specimen N5G1 was 0.1457 , and the squared $R^{2}$ of the correlation coefficient after fitting was 0.97449 . In $10 \% \mathrm{Na}_{2} \mathrm{SO}_{4}$ solution, the damage degree of concrete specimen N10G1 is 0.2025 (Figure 8(b)). The expansion hydrates are produced faster in the concrete, which also produces greater expansion stress. As a result, cracks expand more quickly under the action of high-concentration $\mathrm{Na}_{2} \mathrm{SO}_{4}$ solution (by mass fraction). The greater the $\mathrm{Na}_{2} \mathrm{SO}_{4}$ concentration, the higher the degree of damage and deterioration of concrete.
3.2.3. Influence of Fly Ash Content on Concrete Damage Degree. The variation trend and the fitting curve of the damage degree of concrete with different fly ash contents as the number of drying-wetting cycles increases are delineated in Figure 10.

Figure 10 indicates that concrete specimen N10G1F30 has earlier damage than concrete specimen N10G1F50. With the increase of drying-wetting cycles, the damage degree of concrete specimen N10G1F50 exceeds the specimen N10G1F30. After 90 cycles of drying-wetting, the damage degree of the concrete specimen N10G1F30 is 0.0575 , and the square of the correlation coefficient $R^{2}$ after fitting is 0.93117 . The damage degree of concrete specimen N10G1F50 after 90 cycles of drying-wetting is 0.0623 , and the square of the correlation coefficient $R^{2}$ after fitting is 0.95732 , showing that the fitting accuracy is high. Under the same number of drying-wetting cycles, the damage degree of 


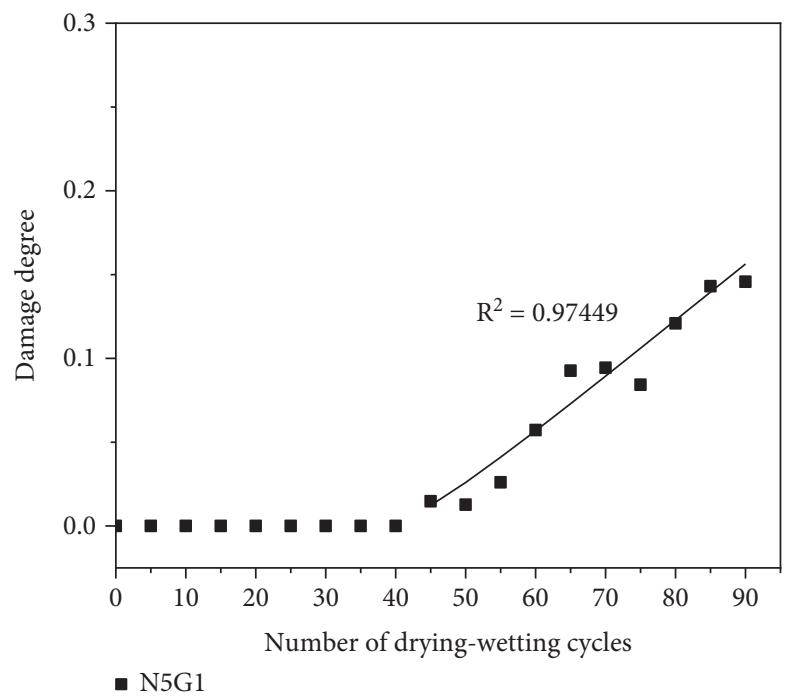

FIgURE 9: Variation of the damage degree of concrete under $5 \% \mathrm{Na}_{2} \mathrm{SO}_{4}$ attack.

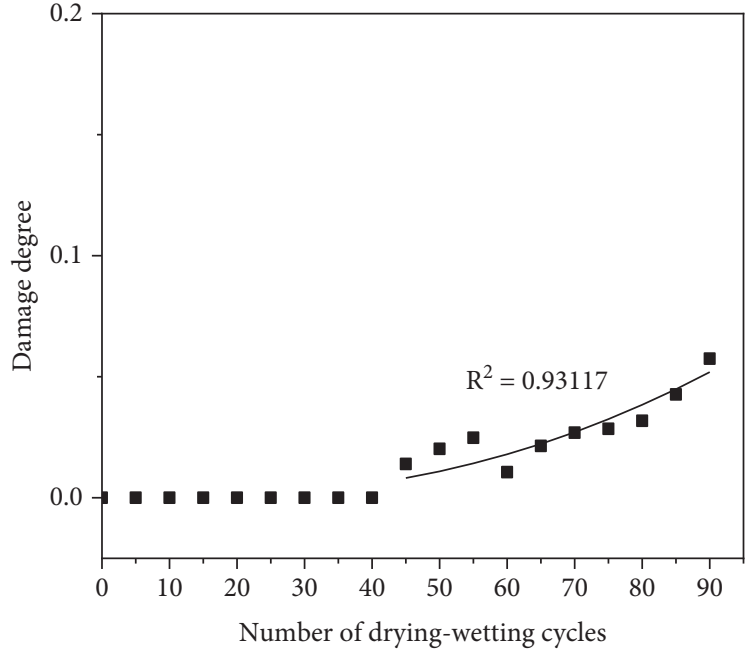

- N10G1F30

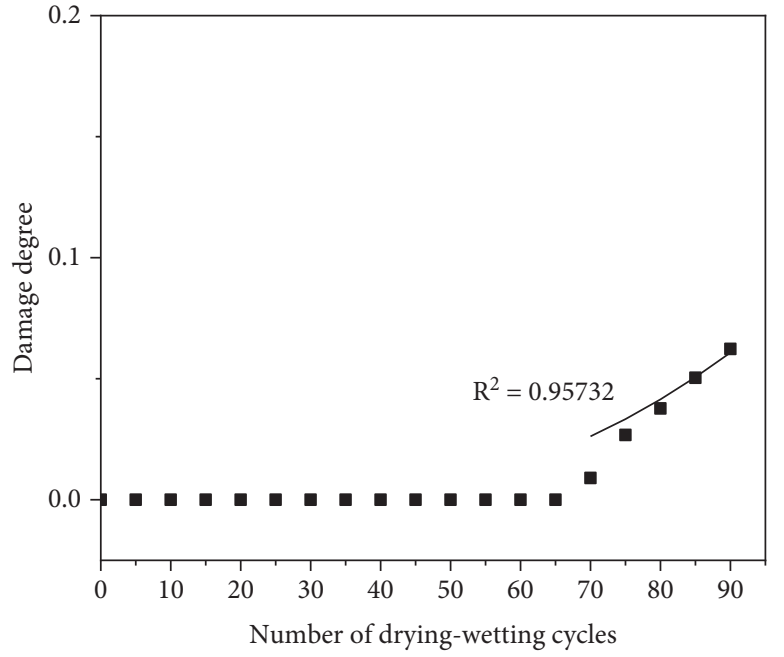

- N10G1F50

(a)

(b)

FIGURE 10: Variation of the damage degree of concrete with different contents of fly ash. (a) N10G1F30. (b) N10G1F50.

concrete without fly ash (Figure 8(b)) is significantly greater than that of concrete with fly ash, which indicates that fly ash can efficiently prevent the damage of concrete to a certain extent. This might be due to the decreasing pore diameter caused by the secondary hydration of fly ash in the existing pores [24]. Of course, it is not necessarily true that the greater the amount of fly ash, the more significant the effect. The proper amount of fly ash can effectively improve the internal structure of concrete to reduce the sulfate corrosion damage.

3.2.4. Influence of Curing Time on Concrete Damage Degree. Figure 11 shows the variation trend and fitting curve of the concrete damage degree with the number of drying-wetting cycles at increasing curing times.
The longer the curing time of concrete is, the less the degree of damage is. The damage degree of concrete specimen N10G1Y90 is 0.1277 after 90 cycles of dryingwetting, and the square of the correlation coefficient $R^{2}$ after fitting is 0.99921 , with good fitting accuracy. The damage degree of concrete specimen N10G1Y300 is only 0.0644 after 90 drying-wetting cycles, and the square of the correlation coefficient $R^{2}$ after fitting is 0.99351 . The initial moist curing time is the key factor that affects the penetration of sulfate ion and the resistance to sulfate attack [25]. The longer the curing time, the more adequate the internal hydration of the concrete and the denser the internal structure. External sulfate attack is less likely to enter, reducing the degree of damage and deterioration to the concrete. 


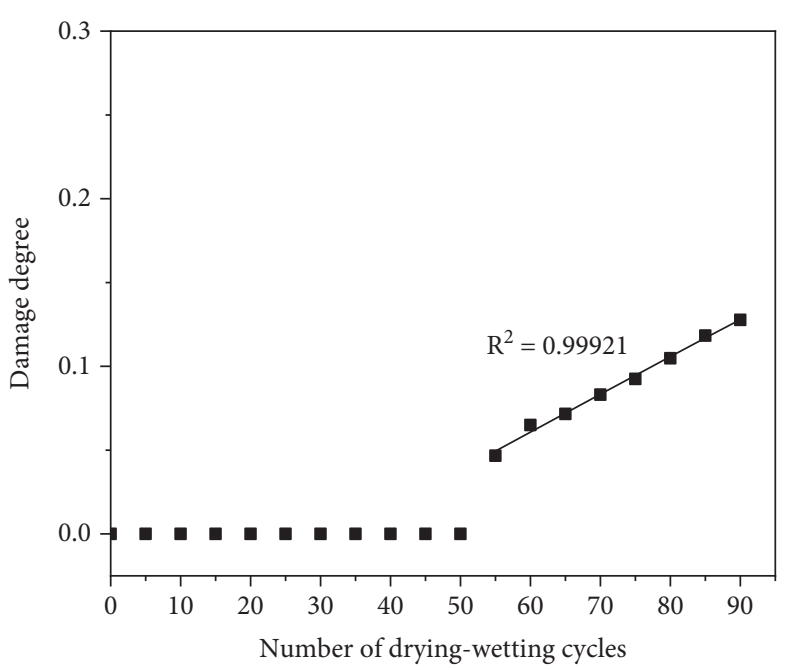

- N10G1Y90

(a)



- N10G1Y300

(b)

FIgURE 11: Variation of the concrete damage degree at increasing curing times. (a) N10G1Y90. (b) N10G1Y300.

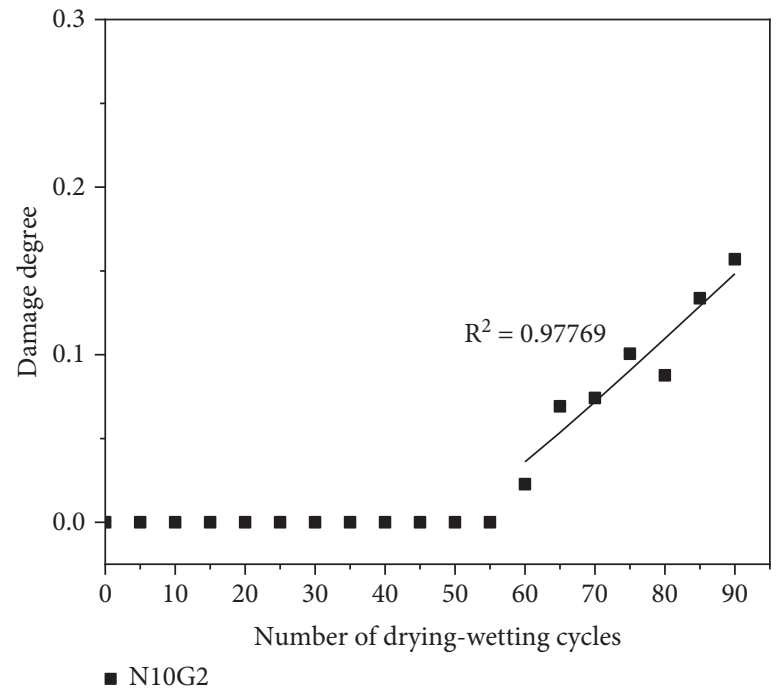

Figure 12: Variation of the damage degree for concrete under different drying-wetting cycle systems.

3.2.5. Influence of the Drying-Wetting Cycle System on Concrete Damage. Figure 12 depicts the variation trend and fitting curve of the concrete damage degree under different drying-wetting cycle systems with drying-wetting cycles. The change law of the damage degree of concrete specimen N10G2 is similar to that of specimen N10G1, while the damage degree of concrete appears later and lighter than specimen N10G1. After 90 drying-wetting cycles, the damage degree of concrete specimen N10G2 was 0.157, and the squared correlation coefficient $R^{2}$ after fitting was 0.97769. Compared with concrete specimen N10G1, the degree of damage is reduced by $22.47 \%$. Chaube et al. [26] pointed out that the evaporation process of water in concrete significantly lags behind the moisture process during dryingwetting cycles; the "ink-bottle effect" was the main cause of this phenomenon. As a result, with the increase of the baking-immersing time ratio, the concrete damage and deterioration will further exacerbate.

3.2.6. Analysis of Model Parameters and Prediction of Concrete Service Life. According to the fitting results of Sections 3.2.1 3.2.5, the parameters in the Weibull distribution model under different service conditions are obtained. Under the action of corrosion, the critical value of concrete damage failure is not clearly defined, while the "quick freezing" test stipulates that the damage of concrete relative dynamic elastic modulus reaches $60 \%$, that is, it is considered to be failed. In view of this, when the concrete damage degree is set to reach $40 \%$, the number of drying- 
TABLE 4: Parameters and predicted life of the Weibull distribution model of each service condition under drying-wetting cycles and sodium sulfate attack.

\begin{tabular}{|c|c|c|c|c|c|}
\hline Specimen code & $\alpha$ & $\lambda_{0}$ & $v$ & $R^{2}$ & SM \\
\hline N10G1 & 2.15919 & 6.29821 & 0.77155 & 0.98299 & 120.4 \\
\hline N5G1 & 1.16598 & 3.85001 & 0.83759 & 0.97449 & 168.8 \\
\hline N10G1R35 & 2.62586 & 4.23766 & 0.98944 & 0.95 & 197.9 \\
\hline N10G1R45 & 2.07062 & 11.8714 & 0.01 & 0.99083 & 90.5 \\
\hline N10G1F30 & 2.45974 & 2.80916 & 1.07924 & 0.93117 & 223.3 \\
\hline N10G1F50 & 2.99746 & 2.57182 & 3.00708 & 0.95732 & 211.4 \\
\hline N10G1Y90 & 1.0639 & 1.8114 & 1.41338 & 0.99921 & 235 \\
\hline N10G1Y300 & 2.79334 & 1.21212 & 3.62692 & 0.99351 & 284.5 \\
\hline N10G2 & 1.18816 & 4.38595 & 1.19739 & 0.97769 & 159.5 \\
\hline
\end{tabular}

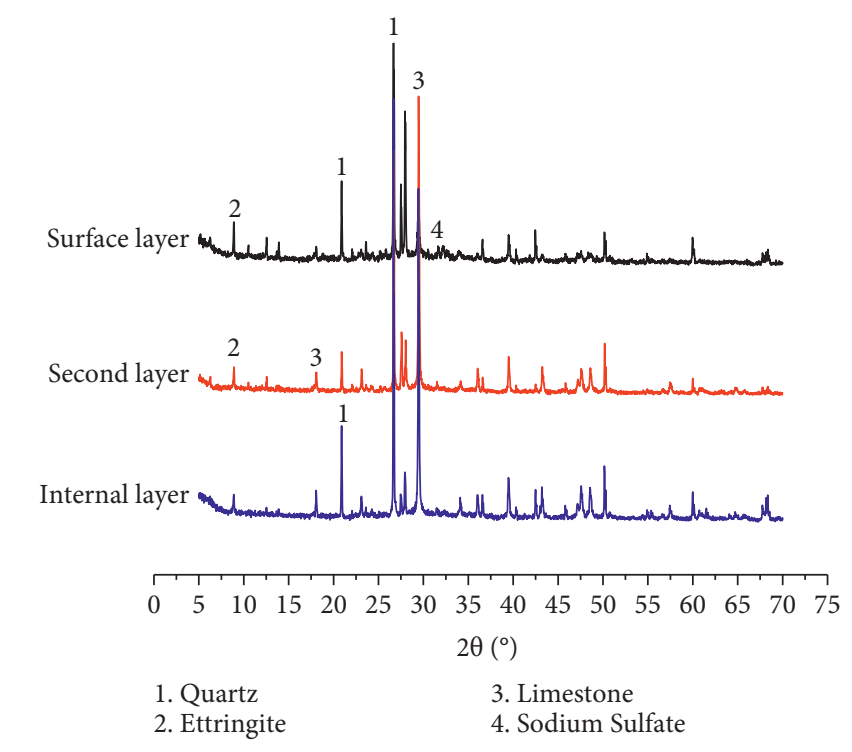

FIGURE 13: XRD patterns at different depths for specimen N10G1.

wetting cycles at this time is the service life of the concrete. The parameters and service life of the model in each service condition are shown in Table 4.

(1) Shape Factor $\alpha$. The shape factor $\alpha$ reflects the failure characteristics of every point inside the concrete. Although the shape factor $\alpha$ is different under different service conditions, the difference is small. The shape factor $\alpha$ varies from 1.06390 to 2.99746 , indicating that the shape of the failure curve at each point in the concrete is approximately the same.

(2) Scale Factor $\lambda_{0}$. The scale factor $\lambda_{0}$ reflects the resistance of concrete to adverse conditions. The larger $\lambda_{0}$, the smaller the material resistance is and vice versa. As can be seen from Table 4, the difference in scale factors of concrete with different water-binder ratios is more obvious. The scale factor $\lambda_{0}$ of the damage model for specimen N10G1R35 is 4.23766 , and the scale factor $\lambda_{0}$ of the damage model for specimen N10G1 is 6.29821. However, the scale factor of the damage model for specimen N10G1R45 is larger, and its value is 11.87140 . It shows that the resistance of concrete decreases significantly with the increase of the water-binder ratio, which is in line with the actual situation. The scale factor $\lambda_{0}$ of the damage model for specimen N10G1Y90 is 1.81140 , and the scale factor $\lambda_{0}$ of the damage model for specimen N10G1Y300 is 1.21212 . The longer the early curing time is, the greater the material resistance is and the smaller $\lambda_{0}$ is.

(3) Gradient Factor $v$. The gradient factor $v$ reflects the difference in damage development between different parts of the concrete. The larger the gradient factor, the greater the difference in damage development at different locations within the concrete and the poorer the synchronization of damage. The gradient factor $v$ of the damage model for specimen N10G1R35 is 0.98944 , and the gradient factor $v$ of the damage model for specimen N10G1 is 0.77155. However, the gradient factor $v$ of the damage model for specimen N10G1R45 is only 0.01000 . The greater the water-binder ratio is, the smaller the damage gradient is and the faster the speed of synchronous damage advancement is. The gradient factor $v$ of the damage model for specimen N10G1Y90 is 1.41338 , and the gradient factor $v$ of the damage model for specimen N10G1Y300 is 3.62692. The longer the early curing time, the greater the damage gradient and the slower the speed of synchronous damage advancement. 
It can be seen from Table 4 that the change law of the predicted lifetime value of concrete is consistent with the damage evolution of concrete. In addition, $R^{2}$ of the specimen N10G1F30 after fitting is $0.93117, R^{2}$ of the other concrete specimens after fitting is between 0.95000 and 0.99921 , and fitting accuracy is relatively high. In the experiment, the damage degree of the specimen N10G1R45 is 0.4046 after 90 drying-wetting cycles, that is, the service life value is reached. The predicted life of the model is 90.5 times, which is very close to the test value. It shows that the Weibull distribution model can accurately predict the service life value of concrete under drying-wetting cycles and sodium sulfate attack.

\section{The Corrosion Products of Interior Concrete}

$\mathrm{X}$-ray diffraction analysis of ground powder samples at different depths was carried out using a D8 ADVANCE X-ray diffractometer manufactured by Bruker AXS Co., Ltd. The XRD pattern obtained from the experiment was compared with the standard diffraction pattern in the database to determine the crystal phase in the sample. XRD patterns at different depths for specimen N10G1 under the combined actions of drying-wetting cycles and sodium sulfate attack after $180 \mathrm{~d}$ are shown in Figure 13.

As can be seen, under the combined actions of dryingwetting cycles and sodium sulfate attack for 180 days, the diffraction peak of sodium sulfate appeared in the corrosion product of the concrete surface layer, except for ettringite. The diffraction peak of the sodium sulfate was very low, which was related to the low sodium sulfate content in the corrosion product. This is the typical characteristic of physical sulfate attack caused by salt crystallization. Thus, it can be inferred that the action of drying-wetting cycles changes the damage mechanism of sulfate on concrete [8]. A diffraction peak of ettringite appeared in the corrosion product of the second layer $(1 \mathrm{~cm})$. There was no diffraction peak of ettringite or gypsum in the corrosion product of the inner layer $(2 \mathrm{~cm})$, indicating that sulfate ions did not erode to the inner layer.

\section{Conclusions}

In this paper, the effect of sodium sulfate attack on concrete incorporated with drying-wetting cycles was investigated. The impact factors (water-binder ratio, the solution concentration of sodium sulfate, fly ash content, etc.) were observed to influence the sodium sulfate attack by the mass loss rate and damage degree at regular time intervals. Also, the hydrates of sulfate-attacked samples were analyzed using $\mathrm{X}$-ray diffraction. The conclusions are summarized as follows:

(1) Compared with the damage degree, the mass loss rate has a certain degree of hysteresis in the durability assessment of concrete under drying-wetting cycles and sulfate attack. After 90 cycles of dryingwetting, the damage degree of the specimen N10G1R45 is 0.4046. However, the mass loss rate is $-2.654 \%$, still a negative growth; thus, the mass loss rate seems not to be an appropriate assessment standard for ordinary concrete under drying-wetting cycles and sulfate attack.

(2) Concrete with a high water-binder ratio accelerates the diffusion of sulfate ions in the wet state. In the dry state, due to the better connectivity of the pores, the crystallization conditions are easier to achieve, which speeds up the process of concrete damage and deterioration. Under high-concentration $\mathrm{Na}_{2} \mathrm{SO}_{4}$ erosion, the sulfate ion content of the concrete erosion layer is relatively high, and the degree of damage is large. Incorporating an appropriate amount of fly ash can effectively improve the resistance of concrete to sulfate attack under drying-wetting cycles.

(3) Longer curing time delays early microcracks of concrete appearance and slows the development degradation. The drying time determines the depth of deterioration of the concrete; with the increase of the baking-immersing time ratio, the sulfate ion erosion and the deterioration degree of the concrete are synchronously intensified.

(4) The trend of the predicted service life of concrete is consistent with the damage evolution. The established Weibull distribution model can accurately predict the service life value of concrete under drying-wetting cycles and sodium sulfate attack.

\section{Data Availability}

The data used to support the findings of the study are available from the corresponding author upon request.

\section{Conflicts of Interest}

The authors declare that they have no conflicts of interest.

\section{Acknowledgments}

This study was sponsored by the Construction System Science and Technology Project of Jiangsu Province (Grant no. 2019ZD001229).

\section{References}

[1] I. Tai, H. Sergio, P. Cavalaro, and I. Segura, "The role of porosity in external sulphate attack," Cement and Concrete Composites, vol. 97, pp. 1-12, 2019.

[2] H. Tanyildizi, "The investigation of microstructure and strength properties of lightweight mortar containing mineral admixtures exposed to sulfate attack," Measurement, vol. 77, pp. 143-154, 2016.

[3] J. Gao, Z. Yu, L. Song, T. Wang, and S. Wei, "Durability of concrete exposed to sulfate attack under flexural loading and drying-wetting cycles," Construction and Building Materials, vol. 39, pp. 33-38, 2013.

[4] F. Xie, J. Li, G. Zhao et al., "Experimental study on performance of cast-in-situ recycled aggregate concrete under different sulfate attack exposures," Construction and Building Materials, vol. 253, pp. 1-13, 2020. 
[5] J. Yuan, Y. Liu, Z. Tan, and B. Zhang, "Investigating the failure process of concrete under the coupled actions between sulfate attack and drying-wetting cycles by using X-ray CT," Construction and Building Materials, vol. 108, pp. 129-138, 2016.

[6] B. Qi, J. Gao, F. Chen, and D. Shen, "Evaluation of the damage process of recycled aggregate concrete under sulfate attack and wetting-drying cycles," Construction and Building Materials, vol. 138, pp. 254-262, 2017.

[7] F. Liu, Z. You, A. Diab et al., "External sulfate attack on concrete under combined effects of flexural fatigue loading and drying-wetting cycles," Construction and Building Materials, vol. 249, pp. 1-10, 2020.

[8] Z. Zhang, X. Jin, and W. Luo, "Long-term behaviors of concrete under low-concentration sulfate attack subjected to natural variation of environmental climate conditions," $\mathrm{Ce}$ ment and Concrete Research, vol. 116, pp. 217-230, 2019.

[9] C. Xiong, L. Jiang, Y. Xu, Z. Song, H. Chu, and Q. Guo, "Influences of exposure condition and sulfate salt type on deterioration of paste with and without fly ash," Construction and Building Materials, vol. 113, pp. 951-963, 2016.

[10] D.-T. Niu, Y.-D. Wang, R. Ma, J.-B. Wang, and S.-H. Xu, "Experiment study on the failure mechanism of dry-mix shotcrete under the combined actions of sulfate attack and drying-wetting cycles," Construction and Building Materials, vol. 81, pp. 74-80, 2015.

[11] W. Luo, J. Xiao-Guang, and Z.-Y. Zhang, "Triaxial test on concrete material containing accelerators under physical sulphate attack," Construction and Building Materials, vol. 206, pp. 641-654, 2019.

[12] L. Jiang and D. Niu, "Study of deterioration of concrete exposed to different types of sulfate solutions under dryingwetting cycles," Construction and Building Materials, vol. 117, pp. 88-98, 2016.

[13] T. Yu and J. Qian, Damage Theory and its Application, National Defense Industry Press, Beijing, China, 1993.

[14] Z. Li, Damage Mechanics and its Application, Science Press, Beijing, China, 2002.

[15] B. Li, L. Yin, and L. Fan, "Analysis on flexural fatigue performance of manufactured sand concrete," Journal of Building Materials, vol. 20, no. 5, pp. 801-806, 2017.

[16] X. Qian Hui, Z. Y. Cao, X. Guan, Q. Li, and X. L. Liu, "Damage to recycled concrete with different aggregate substitution rates from the coupled action of freeze-thaw cycles and sulfate attack," Construction and Building Materials, vol. 221, pp. 74-83, 2019.

[17] W. Dong, X.-D. Shen, H.-J. Xue, J. He, and Y. Liu, "Research on the freeze-thaw cyclic test and damage model of Aeolian Sand lightweight aggregate concrete," Construction and Building Materials, vol. 123, pp. 792-799, 2016.

[18] Y. Guan, W. Sun, and C. Miao, "One service-life prediction model for the concrete based on the reliability and damage theories I: narration and establishment of the model," Journal of the Chinese Ceramic Society, vol. 29, no. 6, pp. 509-513, 2001.

[19] Y. Guan, W. Sun, and C. Miao, "One service-life prediction model for the concrete based on the reliability and damage theories II;: verification and application of the model," Journal of the Chinese Ceramic Society, vol. 29, no. 6, pp. 514-519, 2001.

[20] B. S. Yi Ming, GB/T 50081-2002 Standard for Test Method of Mechanical Properties on Ordinary concrete, Chinesestandard.net, Beijing, China, 2002.

[21] J. Li, F. Xie, G. Zhao et al., "Experimental and numerical investigation of cast-in-situ concrete under external sulfate attack and drying-wetting cycles," Construction and Building Materials, vol. 249, pp. 1-11, 2020.

[22] P. Chao-Ming, J. Xu, J. Wang et al., "Investigation of the process and regime of drying and wetting of concrete," Journal of Building Materials, vol. 16, no. 2, pp. 315-320, 2013.

[23] Z. Tang, W. Li, G. Ke, J. L. Zhou, and V. W. Y. Tam, "Sulfate attack resistance of sustainable concrete incorporating various industrial solid wastes," Journal of Cleaner Production, vol. 218, pp. 810-822, 2019.

[24] M. L. Nehdi, A. R. Suleiman, and A. M. Soliman, "Investigation of concrete exposed to dual sulfate attack," Cement and Concrete Research, vol. 64, pp. 42-53, 2014.

[25] Z. Zhang, Q. Wang, H. Chen, and Y. Zhou, "Influence of the initial moist curing time on the sulfate attack resistance of concretes with different binders," Construction and Building Materials, vol. 144, pp. 541-551, 2017.

[26] R. Chaube, "Multiphase water movement in concrete as a multi-component system," Materials and Structures, vol. 27, no. 170 , pp. $370-372,1993$. 